\title{
Novel Contemporary Guidelines and Dimensions of Occupational Psycho-Social Stress, Psychological Risk Factors and Patternsof the XXI century: Time is in us and we are in time. It changes us and we change it
}

\author{
Rouja Ivanova Nikolova* \\ Medical University, Europe
}

Submission: November 23, 2016; Published: January 19, 2017

*Corresponding author: Rouja Ivanova Nikolova, Associate Professor, Medical University, Faculty of Public Health, Byialo More 8 Street, 1527 Sofia, Bulgaria, Europe, e-mail: nikolovarouja@yahoo.com

\begin{abstract}
Generations of individuals of the XXI century who live in conditions of contemporary globalized world are exposed to the traditional model of psycho-social stress but also to novel guidelines and dimensions of occupational stress dictated by the new imperatives of our times. Recent socio-political process and status of psycho-social stress, knowledge of historical past and present induce novel challenges to human spirit, and generate novel ideas for creativity and action in a globalized world. The process of historical and socio-political development changes the nature of human value system and stress in today's complex global oriented world. The major psychological risk factors, guidelines, dimensions and patterns of the XXI century that are dependent on recent social and political process are: socio-political transition; simultaneous life and work in risk of terrorist attacks; role of the level of control on cognitive functioning; human value system and psychological and social characteristics of totalitarian society and society with unknown face; stressors inducing recent socio-political process; patterns of occupational stress of posttotalitarian and Western societies; impact of intellectual, political, social, and electronic revolutions on human mental workload; the new sociopolitical experiment of the XXI century; human fanatical intolerance of more retrograde regimes to democratic countries; the new sense of generations of XXI century; genetic and cognitive information in different societies; differentiation and discrimination of risk factors; socioeconomic and technological changes affecting work; psycho-social risks affecting health; work in complex human - socio - technical system, factors affecting failure of the system; patterns of cognitive load.
\end{abstract}

Keywords: Occupational psycho-social stress; Psychological risk factors; Socio-political process; Health status risk; Risk of terrorist attacks; Generations of the XXI century; Cognitive load; Human value system; Human/operator; Automation/technology

Abbreviations: NORA: National Occupational Research Agenda; NIOSH: The National Institute of Occupational Safety and Health; HRV: Heart Rate Variability; CVD: Cardiovascular Diseases

Vasil Levski

\section{Introduction}

Generations of individuals of the XXI century who live in conditions of contemporary complex global oriented world are exposed to the traditional, well-developed research-based model of psycho-social job stress but also to novel guidelines, dimensions, scheme and characteristics of occupational stress. Psycho-social characteristics are bound and linked with human value system and human nature. Human values are intransient and in different generations can be retained and maintained, but the process of historical and social development change the nature of human value system in today's complex global oriented world. The major psychological risk factors, guidelines, dimensions, and patterns of the XXI century are dependent on recent stress-induced social and political process, and are dictated by the new imperatives of our modernity. Sociopolitical processs affect and shape lives and behavior of modern generations in normal conditions and particularly under exposure to life and occupational stress. Then why individuals should think about the arising and occurring changes in worldly existence and working life today and their future consequences? Is there anything special that takes place today compared to what previous generations have suffered and experienced? Do we need to learn from the experience, knowledge and complicated process of historical development and related mistakes of previous generations? Are we to believe in the eternal human values? Yes, I think that there are and that we have to Advance in science, information technology, automation and all spheres of 
intellectual, occupational and social development of society of the XXI century has inspired us from the limitless possibilities of the human spirit, intellect and creativity.

\section{Discussion}

\section{Major occupational psycho-social stressors, psychological risk factors, guidelines, dimensions and patterns of the XXI century}

Differentiation and discrimination of risk factors and risk occupations. Genesis, exacerbation and deterioration of health status of risk individuals. Studying physiological regulatory mechanisms inducing diseased states: One of the methods for assessment of occupational psycho-social stress that we apply in our work is the NIOSH job stress questionnaire for occupational stress study [1]. NIOSH job stress questionnaire is adapted for Bulgarian conditions and language. The application of this questionnaire in individuals from different professional groups - operators of chemical plants, air traffic controllers, operators of telecommunications, military pilots, computer operators, employees from healthcare, sound producers, employees of gas construction industry and many other contingents allows their comparison, and facilitates differentiation and discrimination of risk occupations and risk factors for triggering, developing and accelerating stress response, and for determination of working performance. Another important method for the study and assessment of occupational psycho-social stress that I apply in my research studies is the job stress questionnaire that I translated and adapted for Bulgarian conditions and language and with which I am authorized to work in Bulgaria from Job Stress Center.

Apart from immanent basic traditional psychological modus and approach of occupational stress for assessment of psychosocial risk factors at specific working places on the one hand and the impact of psycho-social factors in the work and living environment on the degree of subjectively experienced stress (mental strain, psycho-somatic complaints) on the other, we are witnessing novel guidelines, dimensions and patterns dictating a different scheme and characteristics of occupational stress.

A growing emphasis in medical research and screening of risk factors that we are interested in is the essential role of psychosocial stress on the genesis, exacerbation and deterioration of the health status of risk contingents of individuals, and determination their performance. For example, the program for research occupational (work) studies NORA of NIOSH emphasizes on recent physiological regulatory mechanisms (autonomic, immunological, hormonal, neural) that mediate and induce a wide range of diseases as a result of the impact of occupational stress [2,3]. Determining the functional role of autonomic cardiovascular control (investigated by analysis of Heart Rate Variability) as a mechanism mediating the risk of cardiovascular diseases (CVD) under the effect of psycho-social occupational stress was studied in foreign [4-6] and our [7] researches.
In this regard psycho-physiological significance of Heart Rate Variability (HRV) is expressed in possibility to use it as a reliable method and indicator for occupational stress and workload research, for determining of pattern of functional strain when studying the relationship between autonomic cardiovascular control and psychological and social work-related occupational factors, for identification and definition of these psycho-physiological dependencies that indicate the pattern of functional strain and exhaustion and which might induce CVD, for assessment and prediction of cardiovascular risk, and health promotion at the working place $[2-5,8,9]$.

In our research we are interested in determination of these psycho-social stressors of the working environment that accelerate the process of functional strain and exhaustion as a consequence of chronic prolonged exposure and mediate diseases with stress etiology: cardiovascular diseases, depression and neurosis. The process of functional strain is characterized by stress-induced effects on cardiovascular functional status mediated by neural control mechanisms. The process of cardiovascular functional strain might be accelerated under the influence of psycho-social occupational stress factors and might lead to CVD. In our study on cardiovascular risk and psycho-physiological assessment of occupational stress in shift working telephone operators we found and observed functional dependence of mean heart rate on skill utilization, and functional dependence of short-term variability on cognitive skills and skill utilization [7].

The indicated factors: skill utilization and cognitive skills might exert a stress generating effect and affect the autonomic parasympathetic function and might induce CVD. These results are in agreement with other studies revealing an association between psycho-social occupational factors and cardiovascular functional status controlled by the autonomic and central neural mechanisms mediating CVD incidence [10-13] and support the suggestion of Kristal-Boneh 1995 [14] that HRV might be used for assessment and prediction of cardiovascular risk and performance under the effect of cognitive load, stress and psycho-social occupational risk factors.

Socio-economic and technological changes affecting working activity and health: Another new dimension and trend, as opposed to 50 years of the XX century, when psychological studies were focused primarily on the difficulties and adaptation of employees to the working environment, the present studies highlight and emphasize on major socio-economic and technological changes affecting working activity and their effect on psychological, functional and social status of individuals [2,3].

Socio-political transition: In each new generation many times and multilaterally is underlined the idea that people think, consider and feel they were born and live in a very special period in human history, and that living conditions are changing faster than ever before. Old ideas bound by the relevant public and political development are replaced by new ones with increasing 
speed. If this is true, then each new generation is actually exposed at a faster pace and rhythm of life than previous generations. In Bulgaria my generation lives in the years of socio-political transition - from totalitarian communistic regime to democratic regime. The generation before us of our parents also lived twice in years of complex socio-political transition - first from democratic regime and monarchy to totalitarian communistic regime, and second from totalitarian communistic regime to democratic regime.

The decision of Franklin D. Roosevelt, Winston Churchill and Joseph Vissarionovich Stalin at the Yalta Conference is detrimental and fatal to the lives of millions of people worldwide. Still is difficult to overcome the wounds of the decision to redistribute Europe and shaking off the old communist dictatorship imposed order for the management of post-totalitarian societies in Eastern and Central Europe in the period 1944-1989. These facts impose high mental load on cognitive functioning of freethinking people and indicated generations of individuals who do not profess communistic ideology and acquire novel dimensions of stress. Cognitive mental load of these categories of people deepens and increases in all spheres of intellect and consequent from this type of cognitive load action of the thinking working man, determines concrete and global integrated thought, worldview and ideology of human being.

The new socio-political experiment of the XXI century: The new socio-political experiment of the XXI century is a new form of communism, which was transformed into socialism and professes and declares from some categories of people in posttotalitarian societies and Western societies. In the ideology of socialism is encoded the essence of old communistic ideology dressed in new form that does not change and which is not detected and understand by people living in Western societies. The transformation is invisible and unnoticeable especially for some representatives of Western societies and for the youngest generation of post-totalitarian societies who have not lived in conditions of communism, and hides and brings a risk to democratic values and democratic order and their stability.

Next fact and characteristic of the new socio-political experiment of the XXI century is associated with the new formed socio-political religious order which is based on dictatorship and terrorism and which causes and will continue causing an increasing burden of human mental load and psychosocial stress. These transformations in the socio-political life characterize other novel dimensions of psycho-social stress and cognitive load.

Human fanatical intolerance of more retrograde regimes to democratic countries and strongest regimes of the XXI century and democratic institutions: In our modernity stands and forms the increasingly fanatical, frantic and frenetic intolerance of retrograde regimes to strong democratic states and regimes of the XXI century and their democratic value system, to their prosperous and highly developed economies, to their innovative technologies, ideology, religion and culture. This is an act of attack on civilization. Intolerance degenerates and converts into attack on civilization. This apparent intolerance became apparent only after the beginning of terrorist attacks on the democratic Western societies and their value system. The human value system of Western societies has not allowed and assumed for the existence of primitive "value system" and consolidation of the world of evil. The barrier between the two values systems is hard to overcome and failure to cope with the retrograde mindset loads human psyche and creates a novel guideline, level and form of stress.

The new sense of generations of the XXI century which lives in conditions of democratic regime and value system are facing new imperatives, missions, roles, political compromises and shaterring shock political development: The new mind and way of thinking of the generations of the XXI century are faced with a rapidly changing socio-political reality. This reality dictates new imperatives, creates new roles and performs complex missions, requires political compromises and the socio-political developments in certain cases undergo shattering shock effect. Cognition for these guidelines and collision with these trends cause pronounced degree and level of psycho-social stress, and burdens cognitive workload and functioning.

Generations of the XXI century face a novel level and guideline of psycho-social stress due to continuously growing and unmanageable conflicts, refugee and immigrant waves crises, the lack of stability and even balance: Democratic institutions of the XXI century and the generations of the XXI century are facing a new level and guideline of psychosocial stress due to lack of stability and even balance arising from obscurity and uncertainty that perceives refugee waves, immigrant crises, and unmanaged conflicts of our modernity. Some countries are or were always bright generator of foreign conflicts and clogging them.

Parallel and simultaneous life and work in a constantly growing risk of terrorist attacks: Our generation should comply with avant-garde but atthe same time and detrimental patterns that exist in the field ofpsycho-social stress and the new look of occupational stress thatis raised after the terrorist attacks on the World Trade Centerin New York and Pentagon in 2001, after the terrorist attacks in Paris and in Nice during the National Holiday of France in 2016, after the terrorist attacks inGermany in Munich, Berlin, Cologne in 2016, and after terroristattack in Belgium in Brussels in 2016. Strong democratic states and regimes of the XXI century and their democratic value system are exposed to a greater extent to this type of stress.

The role of the level of control on cognitive functioning during risk of exposure to terrorist attacks: The role of terrorism as a constant stressor and the new emerging stressor - the parallel and simultaneous life and work in a constantly growing risk of terrorist attacks as a new guideline 
of stress should be reviewed by the theorists of psycho-social occupational stress. Theories are strong and well developed, but the practice is different. When in combinations described as high working demands and high level of control, which presents an active working situation and low level of working demands and high level of control, which is described as work related to low level of strain, we add exposure in threatening risk of terrorist attacks, we have to ask the question whether the work situation and activity will continue to be active or in the second combination whether the work will continue characterize with low level of strain. We need to revisit the response, and the ratio and proportion of the level of control to the exposure of threatening risk of terrorist attacks in the two next job situations: high demands combined with low control over the working process, creating high occupational stress and low level of working demands and low level of occupational control, which is described as passive work.

The response of control, which is one of the most vulnerable variables and stressors, to risk of terrorist attacks will be crucial to the emerging level of cognitive load of the working population. This novel form of stress increases significantly the level of cognitive functioning and the resulting consequences for mental and functional status of working individuals.

Human value system and psychological and social characteristics of totalitarian society and society with unknown face: When we analyze the dependence of terrorism on human factors we should not ignore mentality of the "little man" and his advisors and leaders nurtured with malicious feelings and the socio-political environment in which he lives and builds, and to not underestimate him and them. Psychological, social and community-based fundamental of totalitarian societies and societies with unknown face create conditions for dominance of this kind of people.

The system and the nature of the human values of democratic well-developed Western and post-totalitarian societies are preserved and thoroughly organized. Human value system of totalitarian societies and societies with unknown person is also retained for the most categories of people. But there are some categories in which human value system and human nature are dictated and confessed, and is bound of the respective sociopolitical development that changes the mentality and creates people who unshakable believe and profess ideologies that are detrimental to the democratic community, and create its hidden and evident enemies. Such ideological elements were observed also in former post-totalitarian societies. The European Union, NATO, United Nations, the world democratic community and the new democratic institutions of the XXI century have defended the enduring principles of civilization: freedom, progress, pluralism and tolerance without which humanity cannot continue to develop normally. Psychological and social characteristics and value system of indicated categories of the above-described societies are deeply embedded and rigid, and even impossible to change and form new guidelines of stress. To live and work with this system is real and major challenge to the democratic world, since its roots are in venerate, and are built from many generations and decades ago.

Stressors that induce novel socio-political process: In recent decades, where live and work generations of the XXI century, significant changes occurred in occupational life, inducing novel dimensions and patterns in psycho-social stress. More significant professional changes such as the introduction of new technologies at work, the accelerated and fast transition from physical to mental-based cognitive workload, the origination generating and triggering of occupational stress and work in exposure to job stressors, work in the process of functional and psychological interface and collision with automated and intelligent systems, extremely significant for our times and contemporaneity topic for life and work in a constantly growing threat of risk of terrorist attacks, recent social and political complicated dimensions, opening new ways of communication and interface induce new socio-political process of novel challenges to the human spirit and creativity.

A key theme of medical science and ethics in the XXI century is considering and ensuring of optimal health status, optimal physical and psychological efficiency performance and work ability, highly reliable expertise and professionalism to consolidate freedom in the world, to preserve human peace and to guarantee defense of the safety and security against terrorism and tyranny, and to preserve the principles and values of the world democratic community.

Description of some social aspects of self-identity and modernity in the late XX century offers a work of Giddens [15], which however has hues and shades of egocentric abstract thinking and lacks the thought for our reality. It is appropriate to perform adequate comparison of stress-induced psychosocial stress of social and political reality of the XX century and especially in the last half and last decades of the XX century when important changes and shakes occurred in the sociopolitical processes with this of the XXI century. The beginning of the XXI century and modern times in which we live accelerates and transforms sharply the social and political processes and acquires novel guidelines, dimensions, shapes and tendencies of life and psycho-social occupational stress. It is difficult to determine the level of stress in this comparison and which stressors of the XX century and the XXI century will weigh more.

Characteristic patterns of occupational psycho-social stress of the post-totalitarian society. Similarities and differences between post-totalitarian societies and Western societies: Societies change their pace and characteristics of development. Post-totalitarian societies have come a long way of development affecting their lives and work. Regardless of the potential similarities between employees (and human being/ operator) in their adaptation to the increasing demands of work there is pronounced differences between occupational tasks that put complex professionally bound and influenced by 
environment systems of well-developed Western societies and post-totalitarian societies. The difference is due to the high level of psycho-social stress in the latter [16]. The increased level of stress operates and acts on mental cognitive processes.

Operators and workers in Western societies are also experiencing stress, but in most cases it concerns relevant social group and not the entire society, and stressors are different. In these societies, social and economic processes have evolved and were settled in an evolutionary and gradual manner, and these processes have not caused such a conflict and upheaval as in our society.

In the post-totalitarian society we are witnessing a revolution in thinking, work and life as a totalitarian way of life is totally rejected. But now the work is performed in terms of economic collapse, imposing difficulties in adapting to these new requirements - the requirement and the need to acquire new skills, knowledge and abilities; working with new technologies and systems; ignoring the state's role in employment and social status; reduction of the staff of enterprises and governmentsupported and related structures, and so on. Health situation of individuals of Central and Eastern Europe and its relationship with the social, economic and risk factors for cardiovascular and other diseases have been discussed extensively [17-19].

The only difference between the post-totalitarian societies and Western societies is that post-totalitarian societies have passed and experienced communistic regime due to the Yalta Conference. This circumstance is the reason for the high level of life and professional psycho-social stress. Post-totalitarian societies are in its nature democratic societies, but were subjected to repressive totalitarian communistic regime and originating from this regime obscurantist terror. In our modernity, when still exist totalitarian societies and when appeared societies with obscure and unknown origin and face, hiding risks of terrorism, terror and terrorist attacks, post-totalitarian societies can be very useful to the contemporary democratic process with its rich experience from the totalitarian past to determine the correct course of contemporary democratic socio-political process.

We remember the past, we do not forget it and knowing the history between 1944 and 1989 appeal to thinking people it will not happen again, because it hides terror and fanaticism, which generate primitivism. Still are fresh traces of these events and people who have passed and have not returned from the communistic concentration camps. During those years without trial, court and judgment in Bulgaria pass about 500000 people. From 1944 to 1962 in Bulgaria operated 44 concentration camps among the most famous were the camps in the dam Rosica, uranium mines in Buhovo, Belene, Saint Vrach, Kutsiyan, Dupnitsa, Bobovdol, Lieutenant Chunchevo, Bosnia, Nojarevo, Chernevo, Green dol, Zagrad, Skravena, Koprinka, Lovech and many others. The number of people killed by the communist government without trial, court and judgment immediately after 9.09.1944 is unknown. It is also unknown the number killed in concentration camps. Killed and detained in the camps are politicians, intellectuals, clerics, students, officers and wealthy Bulgarians. The motto of the camps was the words and the motto of Stalin: There is a man there is a problem, no one no problem! And Dzerzhinsky: The enemy is never educates, and destroys always and everywhere! Many of those killed and those who died in these camps were given to pigs to no traces and were applied brutish methods of torture and murder.

The horrors of these camps were written many, many survivors told about the tragic fate, their stories are collected in thick volumes [20]. Bulgarian death camps are created by Soviet model. Russia has extensive experience of totalitarian communist regime and terror in the creation of concentration camps after the Bolshevik Revolution in 1917 [21]. Alexander Solzhenitsyn describes terror, repression and killings in Bolshevik and Communist death camps GULag after their creation in 1918 in his book The GULag Archipelago [22]. The hallmark and distinctive mark of the repressive system of communism and its most powerful metaphor becomes GULag - the network-conglomerate of concentration camps in the USSR. It GULag allows even not knowing anything about Marxism-Leninism to face the terrible statistics of genocide that characterize the "most humane social order" in human history.

We risk repeating the past if we do not know it. Knowing the history and these facts helps us to comprehend, assimilate, sift out, and realize the actual and existing causes, guidelines, dimensions and patterns of the psycho-social stress of our modernity, and the guidelines of contemporary sociopolitical process. Distinction of stress of our times is that the transformations in the socio-political processes increase notably and significantly the level of stress both in post-totalitarian and Western societies.

Genetic and cognitive information in different societies: Genetics and consciousness transfer from the past to the modernity concrete and essential for the socio-political process information which induces a novel guideline and level of psychosocial and life stress. Societies differ from one another precisely on specific concrete nature of this information. Qualitative changes in it lead to qualitative changes in the society to which it relates. Notions of historical fate form the basis of historical memory on which a certain volume of real facts and events create and maintain at the distinct individual, his sense of belonging to his community. When the community has its own political organization consciousness of belonging of its members is covered with the consciousness of state affiliation.

The impact of intellectual, political, social, and electronic revolutions on human mental workload: Mental workload as well as stress related to environmental factors and psychological factors affects cognitive functioning, as reflected in the human functional state and performance of working tasks. The functional response of operators and workers is determined by the balance between the demands placed on 
the individual and the resources available and the ability to copy with the requirements of working tasks. One important reason why I think the last decades of human development are outstanding inherently is the intellectual, political, social, and electronic revolutions that dramatically changed the lives of people in the last generation. But this pattern has developed and built gradually. It took considerable time while large groups of people were able to start working and to use the results and outcomes (ideas, creativity, productivity, innovation, technology, equipment, facilities, etc.) from these revolutions. A novel guideline and pattern of life and psycho-social occupational stress is the impact of intellectual, political, social, and electronic revolutions on human mental workload.

Psycho-social risks affecting health status: The occupational stress at the working place is a serious risk factor for psychological and physiological health status of working people, and the consequences of its effects occur in other areas: effectiveness of work, morals, nature and quality of human and collegial relationships, socio-medical context of work, performance, quality and level of social and medical health [2327]. A number of research studies have found that stressors are all demands that present to people the occupational working environment and working place [26,28-39].

These in-depth studies dedicated on the subject and its resulting extensive discussion concludes that working individuals who practice occupations characterized by: a high level of job demands - workload, role conflict, high responsibility, cognitive demands, skills utilization, interpersonal conflicts - conflicts between members of the working group and conflicts between different working groups within the workforce; insufficient opportunity to participate in the management of the working process; low degree of control over the working process; low level of social support from the supervisor and colleagues, family and friends; insufficient satisfaction of employment; under load and overload are exposed at risk of developing cardiovascular diseases and diseases affecting the health status - ulcer disease and other gastrointestinal pathology, neurosis, disturbance of the Autonomic Nervous System and others, and damage to psychological condition - depression, Post-Traumatic Stress Disorder, anxiety, fatigue, hostility, social isolation and others, and changes in behavioral activity of the individual - smoking, excessive drinking, accidents and others.

Psycho-social risks affecting health status, psychological condition and behavioral activity form new dimensions of stress. According to the program of the European Union reduction of occupational stress in the workplace and in the working environment is not only a moral and legal case. Reducing this risk factor has economic, social and medical impact, and effect on the quality of public health. Good economic and social impact suggests relevant health and medical status, performance of working activity, work ability and safety.

Work in large-scale complex sophisticated human - socio - technical system. Factors affecting the failure and collapse of the system: Conditions in more developed countries are complex and cover interactions between individual, organizational, social and international political and social processes. Novel contemporary dimension and pattern of occupational activity is work in the large-scale complex sophisticated human - socio - technical system forming the interaction: human/operator - social characteristics - automation/technology. Progress in scientific medical, psychological and social cognition of human being, design and the development of human being of new information and intelligent technologies and agents, introduced automation of work activity and all areas of avantgarde intellectual professional thought and the dynamics of social development in the XXI century induce novel guidelines of work in today's global world. The contemporary working life provides opportunities to improve our economies and health as well as control and management of novel health risks. Physical occupational risks are reduced but significant increase is the mental and musculoskeletal diseases and injuries especially in young women and groups of people with social and economic problems.

Contemporary theoretical and practical issues treated by the field of research of psycho-biology and physiology of occupational stress are the impact of mental workload and occupational stress in complex human/operator - socio - technical system. To predict future problems and to prevent difficulties in the interaction of human/operator - automation system and in its coordination is necessary to dynamically examine three components of the complex human/operator - socio - technical system: human/ operator, social characteristics, and automation/technology [4042]. To understand the success and collapse of complex system: human/operator - automation we must determine and evaluate the effects of mental workload and stress in complex operating environments, to explore psycho-social factors in the work environment, and design, control and regulation of automated and intelligent systems that promote and enhance work activity of human/operator and ensure the security and safety of life and work [43-53].

We defined a model discriminating human-system/ human-computer interaction. Controllability of work situation, quantitative workload, variance in workload and work satisfaction discriminate human-system from humancomputer interaction [54]. The functional dependence of cognitive demands and work satisfaction on vagal activity assessed by spectral power of cardio intervals in Respiratory Sinus Arrhythmia band (Prsa) could promote future research on the association between cognitive workload, work stress, and performance in considering the role of Prsa as an indirect measure of performance [55] and as a direct indicator of the cardiovascular protective function. In our study we observed a functional relationship between cognitive workload assessed by Heart Rate Variability and Health Risk, and work stress measured with work-related psycho-social factors. Our result is consistent with the result of Hockey et al. [49] who reported a functional association between workload and work stress. 
This century - the present century in which we live poses and imposes ahead demands for adequate functioning, interaction and coordination between human being and intelligent systems. Each side of this interaction could contribute and introduce in the system work safety and defense against terrorism, elimination of critical micro- and macro-ergonomic errors in performance of strategic and/or occupational tasks. Past examples of failure and collapse of the system are not complying with the critical factors: damage and failure in the system components and their interactions; defect and disorder in the system; disturbance in the environmental and in the work safety factors; failure to comply with the human factors - such as accidents in Chernobyl, Bhopal, Three Mile Island and the Exxon Valdez [55]. We, in Bulgaria, continue and will continue to experience the consequences affecting our health status due to Chernobyl accident as a result of human error and lack of competence. In addition to the high degree of cardiovascular diseases in our country is observed a trend of increasing the level of neoplasms. Such data were found in the study of the impact of occupational stress on the health status of sound-operators working in the Bulgarian National Radio [56]. The high degree of neoplasms is due to the result of accident in Chernobyl and to the high level of psycho-social occupational stress.

Patterns of cognitive load. Sub-optimal functional status could induce deterioration and degradation in performance and risk of complications of health status: Optimization and innovation are critical processes necessary for success of work performance in complex systems. Work in conditions and in the interaction of automated, human/operator-socio-technical systems are characterized by the potential risk of variability of its components and parameters [57]. Successful management of automated systems is dependent on the capacity of human/ operator to undertake actions and make decisions under normal, sub-normal and emergency situations. As a consequence the role of the operator is changed by an operator who must follow certain rules and laws to operator who solves the problems and takes the actions $[58,59]$ and the skills and abilities are changed and switched from a psychomotor to cognitive actions and solving problems $[42,60,61]$.

Highly automated tools introduced in the system to contribute human/operator to undertake and make decisions impose novel cognitive and information demands for action at work. Monitoring and management of the system in prolonged periods of time induce a high level of mental workload $[53,62]$. The workload increases and enhances as a result of cognitive effects related to the monitoring and management of processes of automation [48,63]. Implementation of professional tasks in the process of interaction between the human operator with automated and intelligent systems with cognitive context and the possibility cognitive load they cause to change the functional status and under prolonged impact to induce sub-optimal functional state is a new guideline and pattern of psycho-social stress.
Variations in workload require determination of the cognitive capacity needed for the operation and functioning of the operator $[57,64,65]$. An essential novel element of regular human interactions with automated systems is to evaluate and to predict optimal functional status of the operator in the working environment $[63,66,67]$. Sub-optimal functional status could induce deterioration and degradation in performance and risk of complications of health status. Specific psychophysiological measures are reliable indicators of research and assessment of mental workload and stress $[8,41,43,49,64,67$ 71]. These indicators reflect changes in the level of mental effort, and mental and cognitive load of the operator.

Psycho-physiological indicators reveal the level of mental effort required by the operator to maintain the necessary degree of cognitive performance. In the basis of testing and study of the human factor, and the evaluation of complex automated civilians, military and aerospace systems are underlined specific specialized psycho-physiological indicators. These indicators assess the major effects of argumentative compensatory effort in performing job tasks and work activities. Performance of mental tasks requiring a compensatory effort is associated with significant changes in the psycho-physiological parameters in laboratory and field conditions to perform and execute the task, and hypothetically is discussed that these indicators are result of defense reaction that is related to disturbance and reduction of the mechanisms of regulation [64].

In the working activity associated with interaction with highly automated tools demanding and imposing cognitive load, operators are exposed to the influence and impact of psychosocial factors of the work environment. Work related to interface with automated systems requires greater and higher degree of activation of cognitive resources: memory committed to the performance and implementation of the working task or activity, processes of attention, decision making and planning [49]. The high level of cognitive demands required for the performance of work can lead and cause stress response if is associated with low level of control over the work environment $[28,40,62]$.

Requirements to work in the process of interaction with automated and intelligent systems exposed human/operator to an increased level of mental workload and work-related occupational stress. The goal in work with automated systems is to achieve an optimal functional state, to regulate and optimize the level of workload and to improve performance [44]. Prolonged work in terms of increased workload and occupational stress, as well as work activity in critical conditions can induce dysfunctional degree of regulation. Disturbed level of regulation control is associated with a sub-optimal functional state, which can cause degradation and failure in performance and collapse of the system.

\section{Conclusion}

Professional work environment focuses and at the same time reflects through its prism the complex socio-political 
processes of transformation in modern society and determines the behavior and actions of people in optimal, sub-optimal, and critical conditions, and working environment under the effect of cognitive workload and occupational psycho-social stress. The human - operator working in complex human/operator-sociotechnical system is a critical element of this transformation. This complex interaction on the one hand leads to new efficiency, operativeness and performance, and which is the most important to new opportunities for human and social progress. On the other hand the socio-political characteristics of the complex global focused world in which we live delineate another group of risk factors - social, professional and psychological that decrease and reduce opportunities for psychological and physiological human adaptation. Work activity of the individual under conditions of exposure to specific risk factors might be reflected not only in the change of health status, but also affects the performance of individual.

Discussed and treated by the psycho-biology and physiology of occupational stress contemporary and advanced avant-garde research dimensions and patterns of occupational psycho-social stress such as the introduction of new technologies at work, the accelerated and fast transition from physical to mental-based cognitive workload, the origination generating and triggering of occupational stress and work in exposure to job stressors, work in the process of functional and psychological interface and collision with automated and intelligent systems, opening new ways of communication and interface, the impact of cognitive workload and occupational stress on human/operator in the complex automated and intelligent systems and in the complex occupational system: human/operator, social characteristics and automation/technology inspire us to continue in-depth studies in this area.

Progress in scientific medical, psychological and social cognition of human being, the design and the development of human/operator of new information and intelligent technologies, introduced automation of work and all areas of the avant-garde intellectual occupational thought and the dynamics of social and political development in the XXI century generate novel ideas for creativity and action in a globalized world. Critical analysis of existing discussed psycho-social and psychophysiological literature and knowledge of the historical past and present provides us an opportunity to show insight into human nature and define a new group of risk factors that characterize our modernity which are not determined and described.

The novel contemporary guidelines and dimensions of occupational psycho-social stress, major psychological risk factors and patterns of the XXI century defined by us are: Differentiation and discrimination of risk factors and risk occupations. Genesis, exacerbation and deterioration of health status of risk individuals. Studying physiological regulatory mechanisms inducing diseased states; Socio-economic and technological changes affecting working activity and health; Socio-political transition; The new socio-political experiment of the XXI century; Human fanatical intolerance of more retrograde regimes to democratic countries and strongest regimes of the XXI century and democratic institutions; The new sense of generations of XXI century which lives in conditions of democratic regime and value system are facing new imperatives, missions, roles, political compromises and shattering shock political development; Generations of the XXI century face a new level and guideline of psycho-social stress due to continuously growing and unmanageable conflicts, refugee and immigrant waves crises, the lack of stability and even balance; Parallel and simultaneous life and work in a constantly growing risk of terrorist attacks; The role of the level of control on cognitive functioning during risk of exposure to terrorist attacks; Human value system, and psychological and social characteristics of totalitarian society and society with unknown face; Stressors that induce novel socio-political process; Characteristic patterns of occupational psycho-social stress of the post-totalitarian society. Similarities and differences between post-totalitarian societies and Western societies; Genetic and cognitive information in different societies; The impact of intellectual, political, social, and electronic revolutions on human mental workload; Psychosocial risks affecting health status; Work in large-scale complex sophisticated human - socio - technical system. Factors affecting the failure and collapse of the system; Patterns of cognitive load Sub-optimal functional status could induce deterioration and degradation in performance and risk of complications of health status.

Humanity is facing in front of increasingly high barriers for variation and growing level which perceives life and occupational stress. Generating stressful exposure and its impact in the human life span and especially the embodiment and expansion of occupational stress in the recent workforce extend challenges towards social and occupational development in the sphere of health, psychology and in the field of social development and progress. These challenges affect the present and future generations who must understand and follow the main line and the truth about human behavior and existence in conditions of a growing cognitive mental thought focused and oriented towards building a civilized society in which work activity to perform in conditions of a eustress aiming a creative personal expression and realization of individual, contributing to individual's prosperity and social progress.

A number of disciplines of contemporary medicine and psychology with its specific research approaches are aimed strategically towards the issues for individual life and occupational stress and the consequences of its expansion, and the aggressive as well as favorable stressor effects on human existence in life and work related situations. Advanced medical and psychological thought counteracts with its reliable and adequate approaches of the scales that accepts and which is quite possible in the future to accept occupational stress. Presented range of innovative searches of the human intellect, as well knowledge and experience of experts in the field of occupational 
psycho-social stress and cognition, build us realistic and at the same time inspire us grading optimistic to a certain extent attitude for the modes, approaches, methods and resources for neutralization of stressor impact and optimization of physical and mental status of individual in the process of work activity and in the collision with the changing characteristics of today's workforce and performed by her complicated work.

Unlimited possibilities of the freedom of human spirit, intellect and creativity contribute to the study and development of the history of genesis of human spirit, advance and progress and embodiment of the innovative creativity of mentallybased and focused workload and occupational activity, as well eustress as a stimulus for life, work and success in the process of interface and collision with intelligent systems. To predict future problems and to prevent difficulties in the interaction of system and in its coordination, and to prevent its disturbance, degradation and collapse is necessary to dynamically control and manage the contemporary dimensions of occupational psycho-social stress, and the novel psychological risk factors and patterns, and to be reckoned with and direct if it is in our range of possibilities guidelines of modern psycho-social stress, and to examine three components of the complex occupational system: human/operator, social characteristics and automation/ technology, as well the human factor with a goal of defense of human freedom, health status, efficiency, work ability, safety at work, and ignoring the real existing in our contemporaneousness risk of terrorist attacks, and not to repeat the past.

\section{Acknowledgement}

This article I dedicate with appreciation of my mother and my father, of their heritage, wisdom and spirit, of their creed, goals, self-determination and belief in human values who passed through the concentration camps in the dam Rositsa and uranium mines in Buhovo.

\section{References}

1. Tosheva M, Nikolova R (2004) Method for Assessment of Occupational Stress. Social Medicine, XII (4): 26-28.

2. National Institute of Occupational Safety and Health (2002) The Changing Organization of Work and the Safety and Health of Working People. Knowledge Gaps and Research Directions. National Institute of Occupational Safety and Health, DHHS (NIOSH) Publication N 2002 116

3. Goldenhar LM, Lamontagne AD, Katz T, Heaney C, Landsbergis $\mathrm{P}$ (2001) The Intervention Research Process in Occupational Safety and Health: An Overview from the National Occupational Research Agenda Intervention Effectiveness Research Team. Journal of Occupational and Environmental Medicine 43(7): 616-622.

4. Theorell $\mathrm{T}$ (2000) Neuroendocrine Mechanisms/Evidence for Mediating Econeurocardiologic Mechanism. Occup Med 15(1): 117162.

5. Schnall P, Belkic K, Landsbergis P, Baker D (2000) The Workplace and Cardiovascular Disease? Occup Med 15 (1): 1-6.

6. Karasek R (2002) Mental Workload, Overload and Heart Rate Variability. Paper presented at the International Conference: Biomarkers of Stress in Relation to Occupational Health, 4 -8 November 2002, Denmark.
7. Nikolova R, Angelova K, Vukov M, Petrova R (2006) Assessment of Cardiovascular Risk in Shift Working Telephone Operators. Ergonomia IJE \& HF 28 (3): 199-208.

8. Nikolova R (1993) Approbation of the Method for Analysis of Heart Rate Variability under Models of Mentally-Induced Occupational Stress and its Methodological Improvement. Dissertation: Doctor of Medicine. National Center of Hygiene, Medical Ecology and Nutrition, Sofia: Bulgaria 1-176.

9. Heart Rate Variability. Standards of Measurement, Physiological Interpretation, and Clinical Use Task Force of the European Society of Cardiology and the North American Society of Pacing and Electrophysiology (1996) Circulation 93(5): 1043-1065.

10. Belkic K, Emdad R, Theorell T, Cizinsky S, Wennberg A, et al. (1996) Neurocardiac Mechanisms of Heart Disease Risk among Professional Drivers. Swedish Fund for Working Life, Stockholm: Sweden.

11. Huikuri H (1997) Heart Rate Dynamics and Vulnerability to Ventricular Tachyarrhythmias. Annals of Medicine 29: 321-325.

12. Pickering TG (1997) The Effects of Environmental and Lifestyle Factors on Blood Pressure and the Intermediary Role of the Sympathetic Nervous System. J Hum Hypertens 11(1): S9-S18.

13. Vrijkotte TG, Van Doornen LJ, De Gues EJ (2000) Effects of Work Stress on Ambulatory Blood Pressure, Heart Rate and Heart Rate Variability. Hypertension 35(4): 880-886.

14. Kristal Boneh E, Raifel M, Froom P, Ribak J (1995) Heart Rate Variability and Disease. Scand J Work Environ Health 21(2): 85-95.

15. Giddens A (1991) Modernity and Self-Identity: Self and Society in the Late Modern Age. Stanford University Press, Stanford, California, USA pp. 1-264.

16. Nikolova R, Collins S (2003a), Effect of Workload and Stress on Operator Functional State. In: R. Hockey, A. Gaillard, O. Burov (Eds.) Operator Functional State. The Assessment and Prediction of Human Performance Degradation in Complex Tasks. IOS Press, Amsterdam: Netherlands, pp. $303-312$.

17. Gemson DH, Sloan RP (1995) Efficacy of Computerized Health Risk Appraisal as Part of a Periodic Health Examination at the Worksite. Am J Health Promot 9(6): 462-466.

18. Shapiro D, Goldstein I, Jamner L (1994) Psychological Factors Affecting Ambulatory Blood Pressure in a High-Stress Occupation. Clinical Applied Psychophysiology 71-88.

19. Shapiro D, Goldstein I, Jamner L (2002) Blood Pressure in Everyday Life: Interplay of Biological, Psychological, Social, Emotional and Situational Factors. Heart Disease: Environment, Stress and Gender, IOS Press, Amsterdam: Netherlands 337: 314-327.

20. Tzanev S (2009), 1944-1953, 1956-1962, 1984-1989. Chapter X. Ninth Round. The Concentration Camps. In: S. Tzanev (Ed.) Bulgarian Chronicles 2137 BC-2007, Trud and Janet, Sofia and Plovdiv: Bulgaria, Vol 4: pp. 312-339.

21. Volkov S (2000) Conversations with Joseph Brodsky. Fakel Express, Sofia: Bulgaria 1-366.

22. Solzhenitsyn A (1994) The GULag Archipelago. NarodnaKultura, Sofia: Bulgaria 1-1444.

23. Karasek R (1989) The Political Implications of Psycho-Social Work Design: A Model of the Psychosocial Class Structure. Int J Health Serv 19(3): 481-508.

24. Johnson J, Johnsson G (1991) The Psychosocial Work Environment: Work Organization, Democratization, and Health. In: Essays in Memory of BertilGardell. Baywood Pub. Amityville, NY: USA.

25. Karasek R (1998) Demand/Control Model: A Social, Emotional, and Physiological Approach to Stress Risk and Active Behavior Development. ILO Encyclopedia 34(6): 34. 
26. Sauter S, Murphy L (1995) The Changing Face of Work and Stress. Organizational Risk Factors for Job Stress. Psychological Association 1-6.

27. Karasek R, Brisson C, Kawakami N, Houtman I, Bongers P, et al. (1998) The Job Content Questionnaire (JCQ): An Instrument for Internationally Comparative Assessments of Psycho-Social Job Characteristics. J Occup Health Psychol 3(4): 322-355.

28. Karasek R, Theorell T (1990) Healthy Work: Stress, Productivity and the Reconstruction of Working Life. Basic Books: USA 1-373.

29. Dhondt S (1994) Monitoring Occupational Health and Safety in Europe: Time Constraints and its Implications. Leiden: The Netherlands "TNO - Gezondheidsonderzoek" (Netherlands Instit. for Health and Preven).

30. Landsbergis PA, Schnall PL, Belkić KL, Baker D, Schwartz J, et al. (2001) Work Stressors and Cardiovascular Disease. Work 17(3): 191-208.

31. Thayer JF, Yamamoto SS, Brosschot JF (2010) The Relationship of Autonomic Imbalance, Heart Rate Variability and Cardiovascular Disease Risk Factors. Int J Cardiol 141(2): 122-131.

32. Andrew Steptoe, Mika Kivimäki (2012) Stress and Cardiovascular Disease. Nature Reviews Cardiology 9: 360-370.

33. Eller NH, Netterstrøm B, Gyntelberg F, Kristensen TS, Nielsen F, et al. (2009) Work-Related Psycho-Social Factors and the Development of Ischemic Heart Disease: A Systematic Review. Cardiol Rev 17(2): 8397.

34. Schnall PL, Landsbergis PA, Baker D (1994) Job Strain and Cardiovascular Disease. Annu Rev Public Health 15: 381-411.

35. Chandola T, Heraclides A, Kumari M (2010) Psychophysiological Biomarkers of Workplace Stressors. Neurosci Biobehav Rev 35(1): 51-57.

36. Peter R, Siegrist J (2000) Psycho-Social Work Environment and the Risk of Coronary Heart Disease. Int Arch Occup Environ Health 73: S41-S45.

37. Michie S (2002) Causes and Management of Stress at Work. Occup Environ Med 59: 67-72.

38. Bakker A, Demerouti E (2007) The Job Demands-Resources Model: State of the Art. Journal of Managerial Psychology 22(3): 309-328.

39. Kivimäki M, Virtanen M, Elovainio M, Kouvonen A, Väänänen A, et al. (2006) Work Stress in the Etiology of Coronary Heart Disease-a Meta-Analysis. Scand J Work Environ Health 32(6): 431-442.

40. Siegrist J (2002) Adverse Health Effects of Effort-Reward Imbalance - Applying the Model to Eastern Europe. Heart Disease: Environment, Stress, and Gender. IOS Press, Amsterdam: Netherlands.

41. Veltman J, Gaillard AW (1998) Physiological Worklaod Reactions to Increasing Levels of Task Difficulty. Ergonomics 41(5): 656-669.

42. Leroux M (2000) Cognitive Aspects and Automation. Cognitive Engineering in the Aviation Domain. Lawrence Erlbaum Associates 99-133.

43. Wientjes CJ, Veltman JA, Gaillard AW (1996) Cardiovascular and Respiratory Processes During a Complex Decision-Making Task Under Prolonged Isolation. In: Advances in Space Biology and Medicine, JAI Press Inc 5: 133-155.

44. Paris C, Salas E, Cannon-Bowers J (1999) Human Performance in MultiOperator Systems. Human Performance and Ergonomics, Academic Press 329-376.

45. Paris CR, Salas E, Cannon-Bowers JA (2000) Teamwork in Multi-Person Systems: A Review and Analysis. Ergonomics 43(8): 1052-1075.

46. Nikolova R, Radev V, Vukov M (2003b) Functional determination of the operator state in the interaction of humans with automated systems.
The Role of Humans in Intelligent and Automated Systems 26(1): 26.

47. Nadine B Sarter (2000) The Need for Multisensory Interfaces in Support of Effective Attention Allocation in Highly Dynamic EventDriven Domains: The Case of Cockpit Automation. The International Journal of Aviation Psychology 10(3): 231-245.

48. PA Hancock, Raja Parasuraman (1992) Human Factors and Safety in the Design of Intelligent Vehicle-Highway Systems. Journal of Safety Research 23(4): 181-198.

49. Hockey GR, Briner RB, Tattersall AJ, Wiethoff M (1989) Assessing the Impact of Computer Workload on Operator State: The Role of System Controllability. Ergonomics 32(11): 1401-1418.

50. Parasuraman R, Hancock P (2001) Adaptive Control of Mental Workload. Stress, Workload and Fatigue. Lawrence Erlbaum Associates 305-320.

51. RTO Lecture Series (2001) Tactical Decision Aids and Situational Awareness. NATO, RTO-ENP-019.

52. Lundberg U (2007) Workplace Stress. Academic Press, San Diego: USA 871-875.

53. Lundberg U, Frankenhauser M (1999) Stress and Workload of Men and Women in High-Ranking Positions. J Occup Health Psychol 4(2): 142151.

54. Kalsbeek JW (1973) Do You Believe in Sinus Arrhythmia? Ergonomics 1(16): 99-104.

55. Meshkati N (2002) Macroergonomics Root Causes of Large Scale Accidents: Three Mile Island, Bhopal, Chernobyl. Lawrence Erlbaum Associates 331-345.

56. Nikolova R, Tzacheva N (2008) Occupational - Physiological Screening of Risk Factors, Health Risks and Recommendations to Employees and Employers in Bulgarian National Radio. Healthcare Management 8(2): 30-39.

57. Hancock P (1999) Human Performance and Ergonomics. Academic Press 1-397.

58. Flach JM (1999) Beyond Error: The Language of Coordination and Stability. Academic Press, San Diego: USA 109-127.

59. Tan K, Kaber D, Riley J (2000) Human Factors Issues in Implementation of AA to Complex Systems. In the Proceedings of the XIV Triennial Congress of the IEA and the 44th Annual Meeting of the Human Factors and Ergonomics Society 97-100.

60. Corcer K (2000) Cognitive Models and Control: Human and System Dynamics in Advanced Airspace Conditions. Lawrence Erlbaum Associates 13-43.

61. De Keyser V, Javaux D (2000) Mental Workload and Cognitive Complexity. Lawrence Erlbaum Associates 43-63.

62. Hanson EK, Godaert GL, Maas CJ, Meijman TF (2001) Vagal Cardiac Control Throughout the Day: The Relative Importance of EffortReward Imbalance and Within-Day Measurements of Mood, Demand and Satisfaction. Biol Psychol 56(1): 23-44.

63. Scerbo M, Freeman F, Mikulka P (2000) A Biocybernetic System for Adaptive Automation. Lawrence Erlbaum Associates 241-255.

64. Backs R, Boucsein W (2000) Engineering Psychophysiology. Issues and Applications, Lawrence Erlbaum Associates 1-385.

65. Nickerson R (1999) Engineering Psychophysiology and Ergonomics. Academic Press 3-34.

66. Gaillard A, Kramer A (2000) Theoretical and Methodological Issues in Psychophysiological Research. Lawrence Erlbaum Associates 31-59.

67. Fahrenberg J, Wientjes C (2000) Recording Methods in Applied 
Environments. Lawrence Erlbaum Associates, Mahwah, New Jersey: USA 111-139.

68. Mulder G, Mulder L, Meijman T, Veldman J, van Roon A (2000) A Psychophysiological Approach to Working Conditions. Lawrence Erlbaum Associates 139-161.

69. Wilson GF (1993) Air-to-Ground Missions: A Psychophysiological Workload Analysis. Ergonomics 36(9): 1071-1087.
70. Wilson GF (1992) Applied Use of Cardiac and Respiration Measures: Practical Considerations and Precautions. Biol Psychol 34(2-3): 163178.

71. Veltman JA, Gaillard AW (1993) Indices of Mental Workload in a Complex Task Environment. Neuropsychobiology 28(1-2): 72-75.
This work is licensed under Creative Commons Attribution 4.0 License DOI:10.19080/PBSIJ.2017.02.555577
Your next submission with Juniper Publishers will reach you the below assets

- Quality Editorial service

- Swift Peer Review

- Reprints availability

- E-prints Service

- Manuscript Podcast for convenient understanding

- Global attainment for your research

- Manuscript accessibility in different formats ( Pdf, E-pub, Full Text, Audio)

- Unceasing customer service

Track the below URL for one-step submission https://juniperpublishers.com/online-submission.php 